\title{
Facility maintenance management system based on GIS and indoor map
}

\author{
Supattra Puttinaovarat, Suwat Jutapruet, Aekarat Saeliw, Siwipa Pruitikanee, Jinda Kongcharoen, \\ Watchara Jiamsawat, Suchakree Limpasamanon \\ Faculty of Science and Industrial Technology, Prince of Songkla University, Surat Thani Campus, Thailand
}

\begin{tabular}{l}
\hline Article Info \\
\hline Article history: \\
Received Dec 21, 2018 \\
Revised Mar 26, 2019 \\
Accepted Apr 3, 2019 \\
\hline Keywords: \\
Facility maintenance \\
Google map API \\
Indoor map \\
Management system \\
Online maintenance system \\
\hline
\end{tabular}

\begin{abstract}
This research presented a system development approach for facility maintenance management system based on GIS and indoor map in the form of web applications that can be used with all devices and no worries about time limitations. The capabilities of GIS, indoor map, and geospatial data visualization help speeding up facility maintenance management process and create benefits to all concerned parties, i.e., users can notify and follow the data of facility errors at the time; or officers in charge can operate quickly because they can access real-time data. Indoor map display makes it easier to access locations or places of damaged facilities. In addition, the data from the model system presented in this research can also be applied to planning and decision-making of executives.
\end{abstract}

\section{Copyright @ 2019 Institute of Advanced Engineering and Science.} All rights reserved.

\section{Corresponding Author:}

Supattra Puttinaovarat,

Faculty of Science and Industrial Technology,

Prince of Songkla University, Surat Thani Campus,

Surat Thani, 84000, Thailand.

Email: supattra.p@psu.ac.th

\section{INTRODUCTION}

In the past, maintenance notification of facilities in classrooms, university buildings, or in offices/agencies was done through a number of approaches, i.e., maintenance documents, phone calls, notification via social media such as Line and Facebook, and notification through particular developed systems. Each of such approaches basically contained different limitations or issues. To clarify, maintenance documents caused operational delay as we had to contact with officers in charge. And large quantities of papers were wasted for the operation. For the limitations of phone calls, sometimes the officers might forget the notification data; and thus operational delay occurred. Above all, if those officers already had loads of works, notifiers had to contact them several times. Today, with the evolution and advancement of IT as well as internet networks along with the popularity of online social networks, some are exploited as channels for facility maintenance notification, for example, Line and Facebook. The advantages are 1) notifers can leave messages even if officers in charge are not available that time; and 2) those social media are convenient and fast contact channels. However, many limitations still remain. To describe, notified data are neither wellorganized nor systematically stored; data forms are unclear; and notifiers cannot be identified or verified clearly. As a result, unreliable junk data appear and it does affect the operation of the officers, because they are unable to differentiate facts and lies. They also fail to manage the data in the system between "under maintenance" and "waiting for maintenance." What's more, the notification data cannot be reported for analysis and future planning. A report of top 10 damaged facilities or a report of average life of each particular type of facilities, for instance.

Due to limitations of usage, maintenance notification approaches, and the use of online social networks, the notification is suggested to be done via application or web applications specifically designed 
for this matter, e.g., notification via Electronic Maintenance or E-Maintenance [1] and via web applications [2]. Asset management systems are also developed based on GIS via desktop applications for data management, display, and report [3]. Nonetheless, those applications still have limitations. They can be used with programmed computers only, and they cannot work with real-time operation. So, they are neither convenient nor fast for use. According to the analysis of the research papers aforementioned, there are some advantages of the development of facility maintenance management system. To illustrate, systematic data storage and management is provided. Notifiers can be identified or verified. These help officers in charge operate more efficiently. Involved persons can follow maintenance status via internet networks. Besides, reported data can be submitted for planning and decision making. But despite the advantages of application and web application development approaches, some limitations still exist. Displayed locations or places of facility notification (Where facilities are damaged) are in the form of Management Information System, which displays results in texts only. Computer facilities in UD266 at U Building could not be turned on. This means the data identified the location in texts, impinging on the operational process of officers in charge. In other words, the delay occurred because they wasted time finding the room in the building. If in case of a large agency with multiple buildings, floors, and rooms, more delay in fixing issues or facility maintenance shall occur. And if officers in charge are new, it even takes some times to explore the layout of the agency as well as rooms. And this will bring the operational delay, too. Thus, with reference to all issues and limitations as stated, this research presented a development approach for facility maintenance management system based on GIS (Geographic Information System) and indoor map. This approach makes the overall operation faster. It stores and displays geospatial data, leading to more convenient operation. Officers in charge do not need to study building layouts in details before the operation. They can simply take the data for planning and decision making. Moreover, the developed system can also be manipulated in other aspects, e.g., the display of rooms and buildings for personnel of an agency.

\section{MATERIALS AND METHOD}

The details of this part included study area and related theories as well as techniques, i.e., Geographic Information System, Google Maps API, and indoor map. To implement the research, system analysis and design, and the model system development were focused.

\subsection{Study area}

The study area of this research for the system development and application was Prince of Songkla University, Surat Thani Campus. The main objective was to apply the developed system for fixing issues or limitations of traditional facility maintenance notification. The model system presented in this research can be applied in educational institutes or any agencies.

\subsection{Geographic information system}

Geographic Information System is a process related spatial information by computer system. The data and information associated with the spatial location, such as the relative position of the map. In addition, it can help to convey meaning-ful changes in time-related information. It can used as a tool to collect data for analysis and display. At present, geographic information system is popularly used for many aspects such as analyzing proper location, managing transportation routes by showing with various patterns for instance, web application and application via mobile device or smartphone [ 4, 5]. For facility maintenance notification and asset management, GIS was applied to crate building layouts of the university in the form of Desktop Application [3].

\subsection{Google Map API}

Google Maps API is a tool for program development or for application websites with Google Maps as part of desired webpages [6] written in HTML codes, JavaScript, and other computer languages such as PHP, Java, etc. [7, 8] in order to develop websites or applications as desired. Google Maps API was capable of map data display. The advantage of Google Maps is that maps and satellite images are with high quality and cover all surfaces of the earth under different scales. To extend what Google already provides, therefore, does not require rare and expensive resources. Furthermore, Google Maps API is an open source program [9] with JavaScript. Programmers can access it to see program code details, and to revise or modify the program. That is why Google Maps API has been widely used today in several aspects, i.e., attractions recommendation and road accident reports [10]. However, for facility maintenance notification, the program has not been applied yet. 


\subsection{Indoor Map}

Indoor Map is a map displaying the inside of buildings. Now, there is a service from Google called Google Indoor Map for agencies to present data of layouts or maps of their buildings. Most agencies relying on this service are business agencies like department stores. The main objective is to facilitate customers to find shops or department customers want to go. For example, it is used in shopping malls in Tokyo to help customer find shops [11]. Besides, it is also used to find expected departments, along with the analysis of customer quantities in each department so as to support customer decision making on heading to their desired departments [12]. This service is also introduced to hospitals for facilitating patients and their relatives when going for hospital services in different units. Therefore, there is no problem of getting loss or wasting time finding units [13]. When studying the application of this service in term of education, it was found that the service is used in building layout mapping to guide the way inside university buildings [14]. However, after reviewing associated literatures, this service has not been applied to facility maintenance notification yet. This research, therefore, developed indoor map technique to be used for facility maintenance notification. The program used in the research was not Google Indoor Maps but the developed indoor map program and Maps API for more convenient and faster development process.

The hardware and software used in the system is shown in Table 1. It is classified into two parts: the hardware and software for the client device and the hardware and software for the server, which have different details. For the client part, it is comprised of two parts, which are the smartphone to detect location data of user, which can be Android or IOS. For the server, it consists of the specific software such as the operating system, application software, connection, web server, and database.

Table 1. Hardware and software specification

\begin{tabular}{|c|c|c|}
\hline & Standard Client & Standard Server \\
\hline Hardware & $\begin{array}{l}\text { - Smartphone } \\
\text { - Tablet }\end{array}$ & - Microcomputer \\
\hline System Software & $\begin{array}{l}\text { - Android } \\
\text { - IOS }\end{array}$ & - MS Windows 8 or upper \\
\hline Application Software & - Web browser & $\begin{array}{l}\text { - Apache } \\
\text { - MySQL } \\
\text { - Google Map APIs } \\
\text { - PHP } \\
\text { - JavaScript } \\
\text { - CSS } \\
\text { - Bootstrap }\end{array}$ \\
\hline Network & - 3G/4G/Wi-Fi & $\begin{array}{l}\text { - Dual } 100 \mathrm{Mbps} \\
\text { - Internet }\end{array}$ \\
\hline
\end{tabular}

\subsection{System analysis and design}

Database analysis and design is generally based on functions or main capabilities of the system so that data is stored comprehensively and completely used. This research presented main capabilities of the system via Use Case diagram as shown in Figure 1. It was found that involved persons or users could be divided into 3 groups, namely, students, lecturers, and officers. The figure showed the relations between system capabilities and each group of users. For the students, they involved with the system in the sense that they could retrieve the data of their classrooms to guide them to the buildings. For the lecturers, they had more rights than the students as they could add facility maintenance notification data in classrooms; and could check maintenance status. For the officers, they had full rights as they could add classroom data or facility data of each particular classroom. They could check maintenance status from lecturers. They could update maintenance status of facilities under maintenance or those finished. In addition, they could write any related reports to propose to executives for their decision making or planning. The algorithm for this research is divided into two mehods as shown in Tables 2 and 3. 


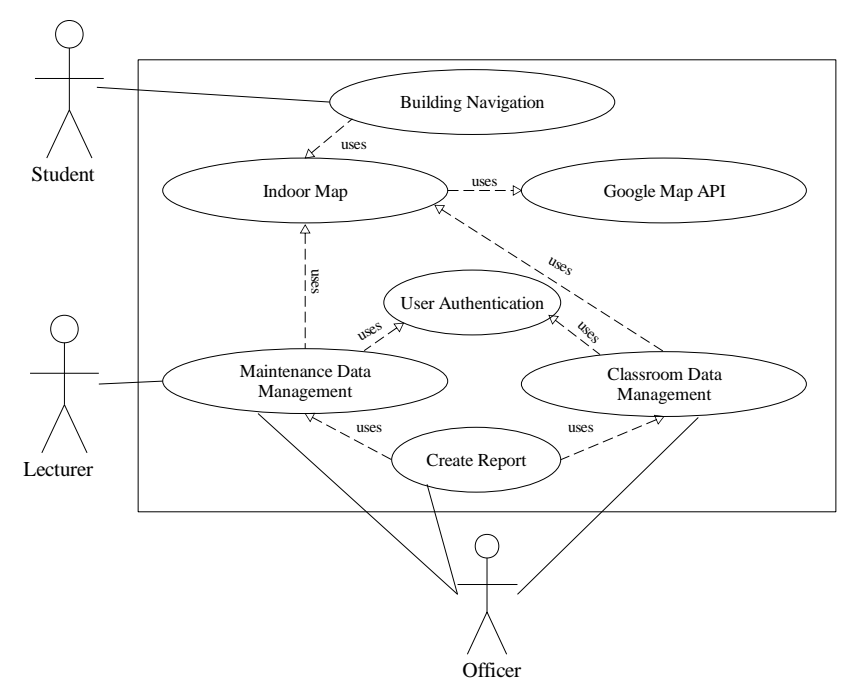

Figure 1. Use case diagram

Table 2. Navigation algorithm

\begin{tabular}{|l|}
\hline Navigation Algorithm \\
\hline Ourdoor Navigation \\
Read GPS Signal; \\
If GPS Signal is Valid \{ \\
Get Current user's location; \\
Select Building name destination; \\
Show Navigation \& Street Map; \\
\} \\
Else \{ \\
Show Warning Message; \\
\} \\
\hline
\end{tabular}

Table 3. Navigation algorithm

\begin{tabular}{|l|}
\hline Maintenance Data Management Algorithm \\
\hline User Authentication \\
Input Username and Password; \\
If Username and Password is Valid \{ \\
Select Building Name; \\
Select Floor; \\
Get Current Latitude and Longitude; \\
Get Room Number and Name; \\
Insert Maintenance Detail data; \\
Show Indoor Map \\
E \\
Else \{ \\
Show Warning Message; \\
Check User Authentication \\
\}
\end{tabular}

\subsection{System development}

The development of facility maintenance model system in this research consisted of the certain development tools, i.e., languages (PHP, JavaScript, CSS, Bootstrap, and Google Maps API); software as a host for application service (Apache); and software for data system storage (MySQL). The development tools mainly included open source software program, because it had no costs or expense of this development work. This research presented 2 functions that helped the efficiency of facility maintenance management, i.e., login (to verify the rights of each group of users owing to their different rights for system use); indoor map display in each university building (to guide users to the buildings and to find classrooms; classroom management; tool data management; facility maintenance notification; notification data management); and submitting reports. 


\subsection{Data collection and performance evaluation}

This research conducted a survey of 20 users about their satisfaction with Facility Maintenance Management System based on GIS and Indoor Map. A questionire that included 7 question. There were 3 questions about at the functionality performance, 2 question about the usability performance and 2 question about reliability performance as shown in Figure 2.

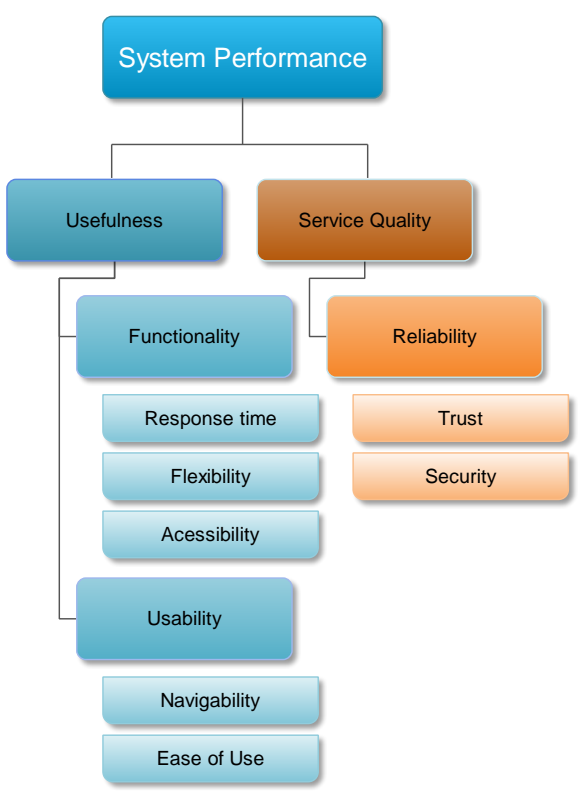

Figure 2. System performance evaluation

\section{RESULTS}

For the results of model system design and the development for facility maintenance management system based on GIS and indoor map, the details were explained as follows:

a. The first part was the comparison between indoor map and no indoor map for the development as shown in Figure 3. Figure 3 (a) was the use of Google Maps API with no indoor map. It could be noticed that only building images and names were displayed. Neither layout nor map was displayed. In contrast, Figure 3(b) displayed the building layout. Users could choose their target floors to see the data.

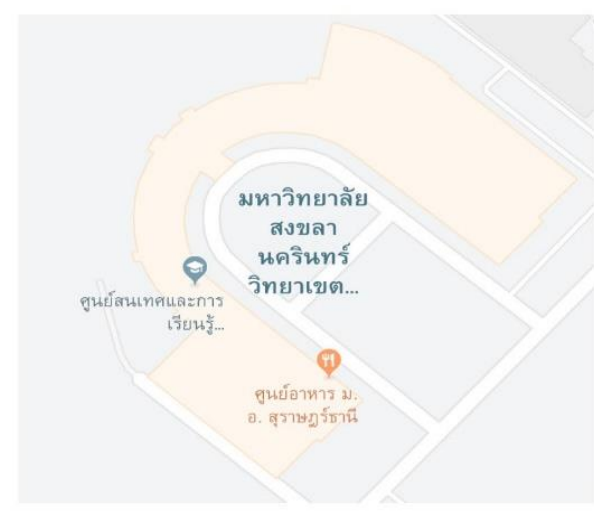

(a)

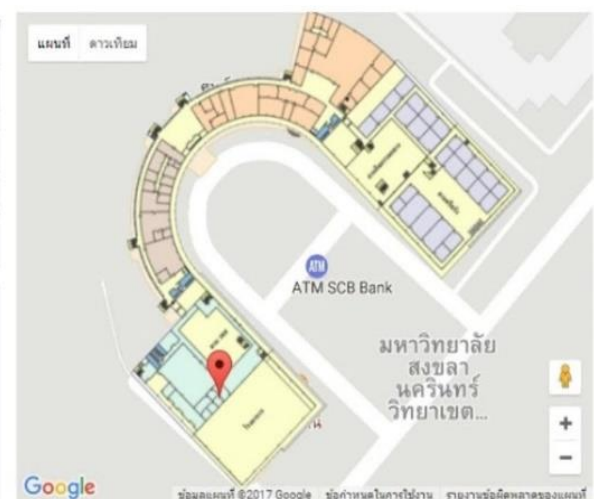

Select Floor $\quad$ G $\begin{array}{llll}1 & 2 & 3\end{array}$

Figure 3. Google Map API results a) Without Indoor Map b) With Indoor Map 
b. To check the rights of each group of users, username and password were required for verification so that notifiers of facility maintenance could be confirmed as shown in Figure 4.

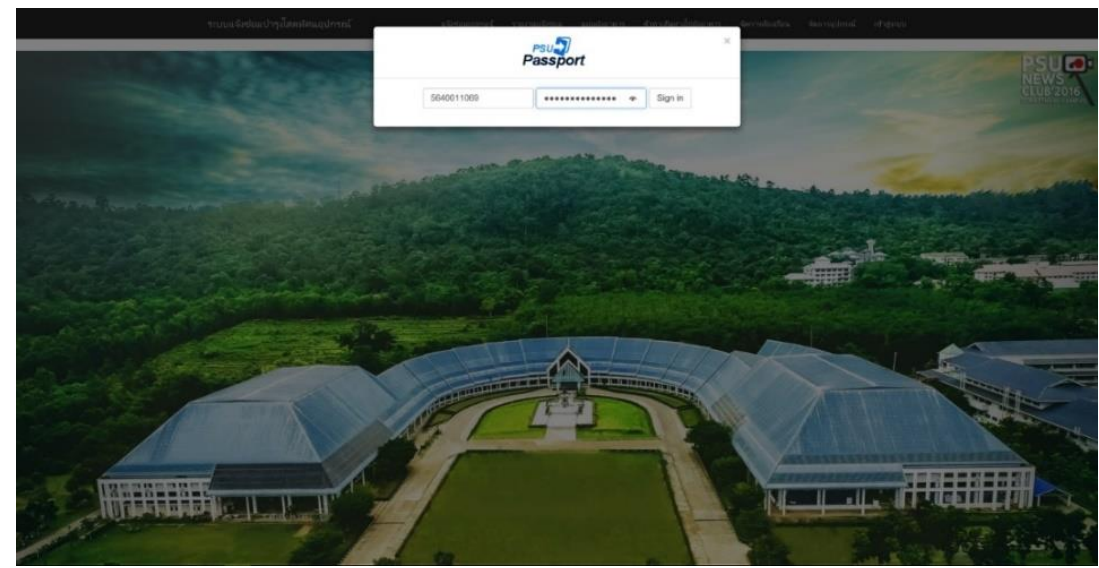

Figure 4. User interface of user authentication

c. Classroom and facility data management in this part must be handled by officers in charge. Such da-ta of each classroom could be added. To add classrooms could be displayed in the form of indoor map as shown in Figure 5.

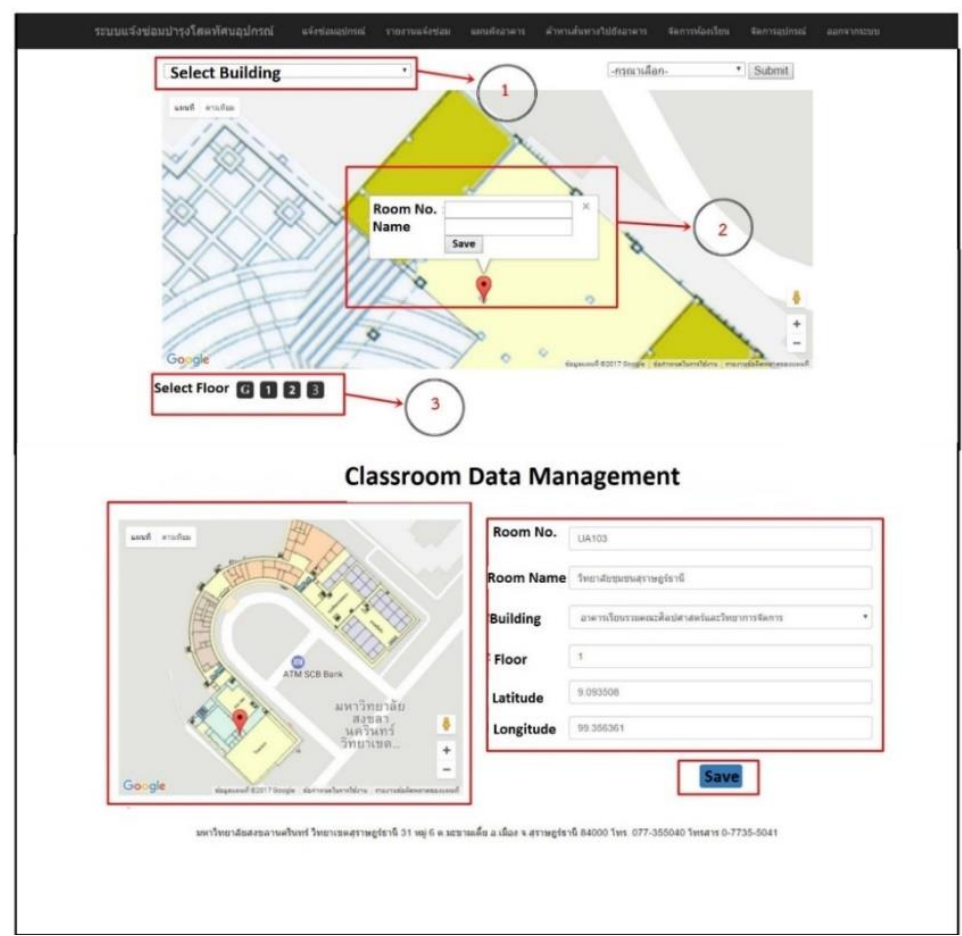

Figure 5. User Interface of Classroom Data Management

d. For facility maintenance notification, notifiers could select buildings, classrooms, facilities, and damaged facilities. Other details, i.e., notifier name, date of notification, contact number, and email, the system would be retrieved automatically from user accounts that users used for login to the system as shown in Figure 6. 


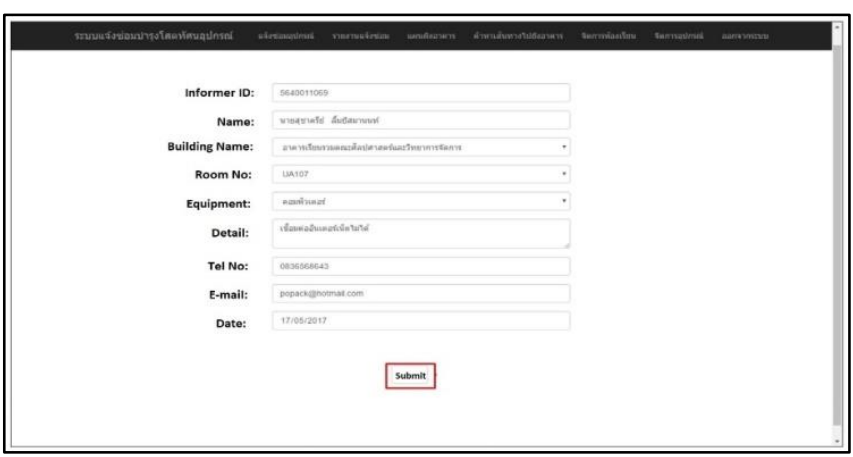

Figure 6. User interface of maintenance data management

e. For the result display in the form of indoor map, when damaged facilities of any classrooms were notified, a red pin was displayed in those rooms on indoor map. as shown in Figure 7. Thus, this part helped officers in charge to access and acknowledge which particular classrooms or locations were with damaged facilities. In addition, when users wanted to check the details of those facilities in each room, they simply clicked the red pin, and then the window showing the details came up along with photos and conditions of damaged facilities as shown in Figure 8.

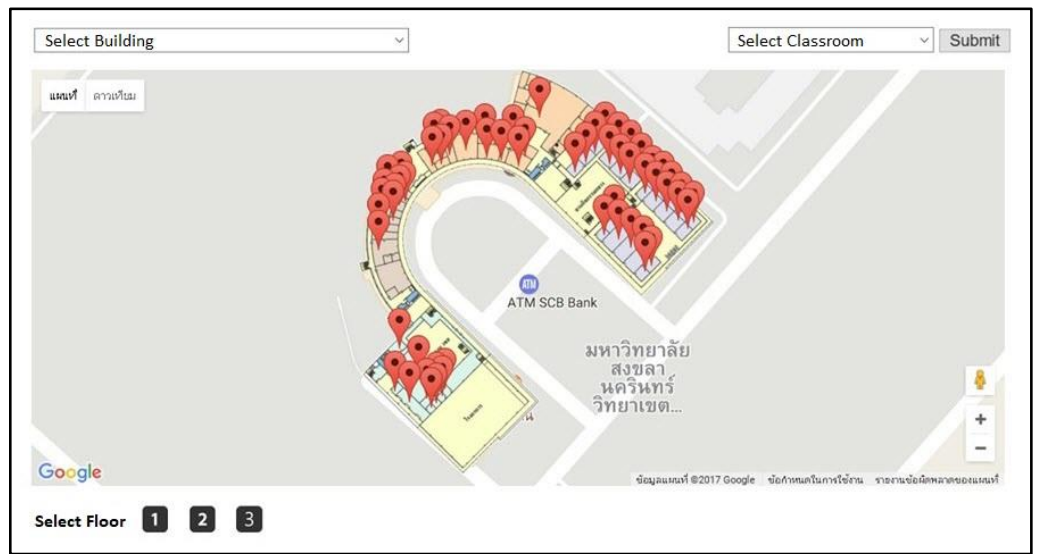

Figure 7. User interface of indoor map

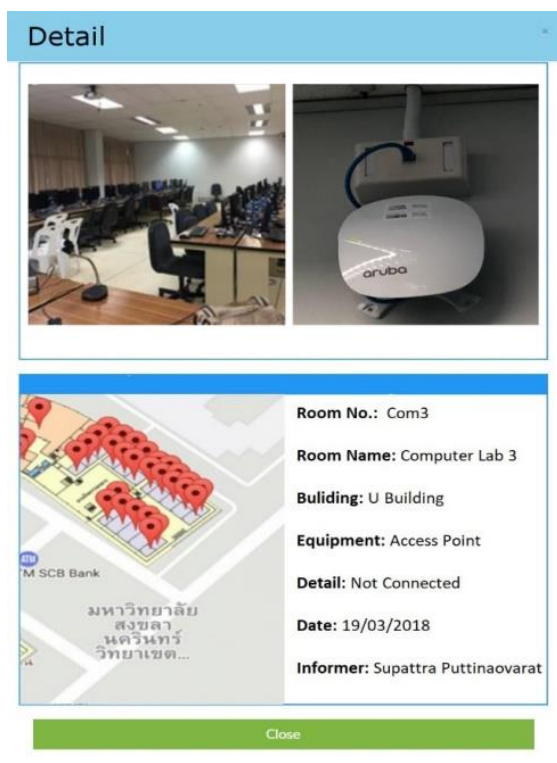

Figure 8. User interface of maintenance detail data 
f. To submit reports of damaged facilities, officers in charge could so and could revise maintenance status so that users were able to follow the current status of their notified facilities as shown in Figure 9. The reports could also be submitted to executives in the forms of graph, MS Excel, and PDF for their further planning and decision-making.

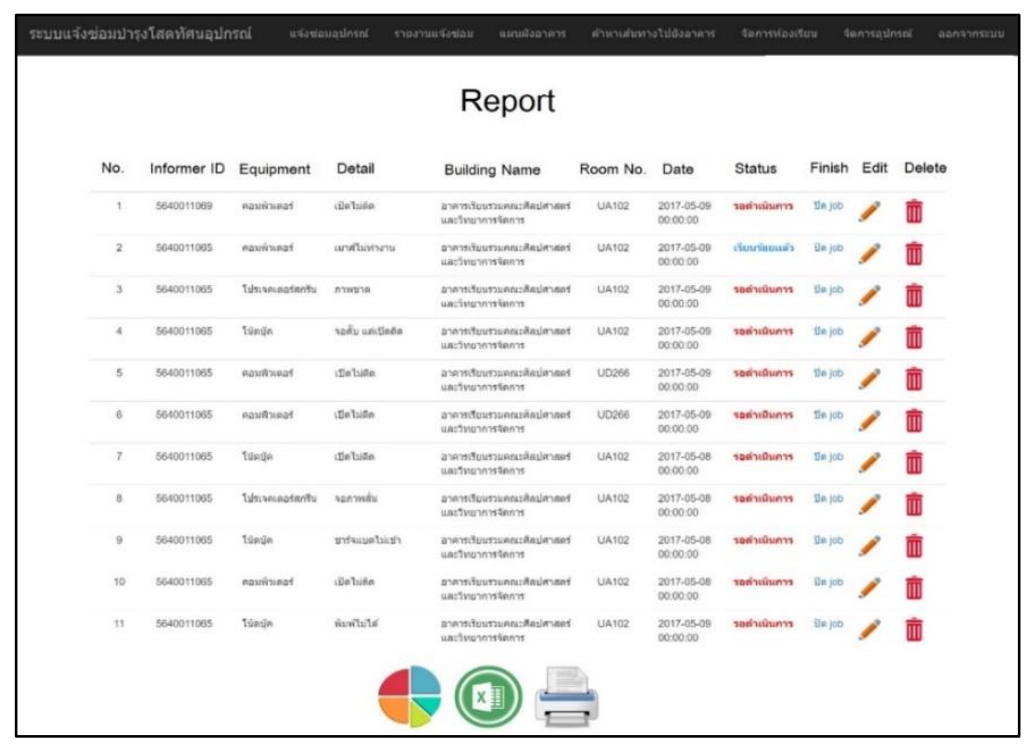

Figure 9. User interface of report

g. For finding and direction, all groups of users could manage this part by selecting their target buildings. Starting points and terminals must be specified. The results were displayed in the forms of map and street map as shown in Figure 10.

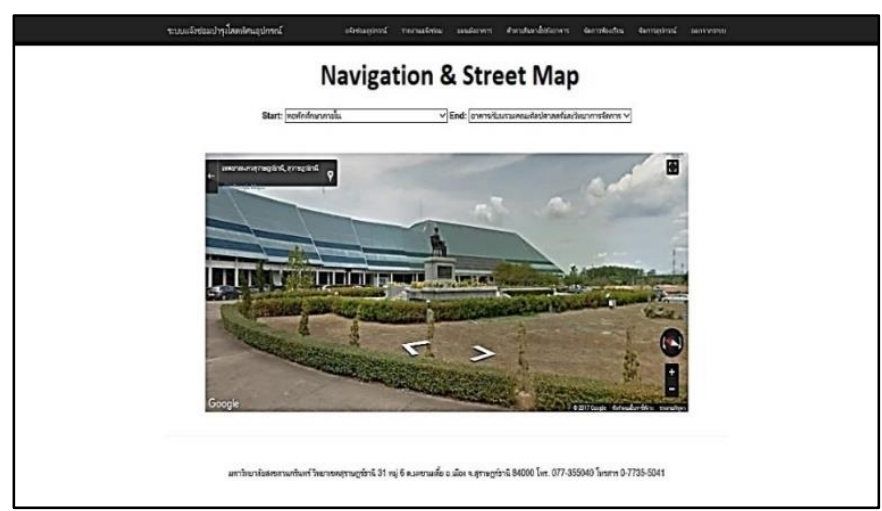

Figure 10. User interface of navigation and street map

Descriptive Statistics were taken to mesure the level of each item. A five point Likert scale was used. With 5 for "Very agree" and 1 for "Very disagree". Any answer with an average of above 3.0 was considered to be good as this indicated the level of the respondent's agreement to those statements representing the tested items. Result form the descriptive analysis as shown in Table 4. 
Table 4. Descriptive statistics (mean score of user satisfaction)

\begin{tabular}{cc}
\hline Satisfaction & Mean \\
\hline Functionality & $\mathbf{4 . 4 0}$ \\
- Response time & 4.54 \\
- Flexibility & 3.89 \\
- Accessibility & 4.78 \\
Usability & $\mathbf{4 . 7 1}$ \\
- Navigability & 4.73 \\
- Ease of Use & 4.69 \\
Reliability & $\mathbf{4 . 6 7}$ \\
- Trust & 4.58 \\
- Security & 4.76 \\
\hline
\end{tabular}

From the descriptive statistics for the item in the Table 4, the item with the highest mean (4.78) is "Accessibility" and the item with the lowest mean (3.89) is "Flexibility". However, all of these items have a mean of above 3 .

\section{CONCLUSION}

According to the results of the model system development presented in this research, it was found that the use of the developed GIS system and indoor map engendered tools or software that facilitated all involved parties. To elucidate, the students had the tools to guide/direct them to school buildings; and to find classrooms in each building. The lecturers could simply notify the maintenance of damaged facilities in classrooms of buildings in a short time; and could follow maintenance status. Officers in charge could acknowledge maintenance notification data and layouts of buildings in which damaged facilities remained, leading to faster maintenance operation. Different types of reports could be submitted for analysis in many aspects to help decision making, for example, reports of the most frequent damaged facilities. The reports presented to executives were supporting documents to consider the next purchase. This research could fix the limitations of the previous facility maintenance system for more efficient system management process.

\section{ACKNOWLEDGEMENTS}

This research was financially supported by Prince of Songkla University, Surat Thani Campus.

\section{REFERENCES}

[1] A. Muller, A. C. Marquez, and B. Iung, "On the concept of e-maintenance: Review and current research". Reliability Engineering \& System Safety, Vol. 93 No. 8, pp. 1165-1187, 2008.

[2] J. H. Lee, M. S. Lee, S. H. Lee, S. G. Oh, B. H. Kim, S. H. Nam, and J. S. Jang, "Development of computerized facility maintenance management system based on reliability centered maintenance and automated data gathering," International Journal of Control and Automation, SERSC, Vol. 6 No. 1, pp. 1-12, 2013.

[3] H. I. El-Gamily, and K. Al-Rasheed, (2015). "Deploying an Interactive GIS System for Facility and Asset Management: Case Study-Ministry of Education, Kuwait," Journal of Geographic Information System, Vol. 7, No. 2, pp. 191, 2015.

[4] M. Ancona, N. Corradi, A. Dellacasa, G. Delzanno, J. L. Dugelay, B. Federici, and J. Stephens, "On the design of an intelligent sensor network for flash flood monitoring, diagnosis and management in urban areas position paper," Procedia Computer Science, Vol. 32, pp. 941-946, 2014.

[5] J. Sunkpho, and C. Ootamakorn, "Real-time flood monitoring and warning system," Sonklanakarin Journal of Science and Technology, Vol. 33 No. 2, pp. 227-235, 2011.

[6] M. Liang, J. Guerra, and P. Brusilovsky, "Building multi-layer social knowledge maps with Google Maps API," In Proceedings of Workshop on Semantic and Adaptive Social Web (SASWeb 2012). University of Pittsburgh, 2012.

[7] S. Choimeun, N. Phumejaya, S. Pomnakchim, and C. Chantrapornchai, "Tool for collecting spatial data with Google Maps API," U-and E-Service, Science and Technology, pp. 107-113, 2010.

[8] D. A. AbdulMonim, Z. H. Muhamad, B. Alathari. "Using the object mapping approach from analysis to implementation for developing student registration system," Indones. J. Electr. Eng. Comput. Sci, Vol. 14 No. 2 , pp. 1030-1038, 2019.

[9] K. Lee, "Technical architecture for land monitoring portal using google maps API and open source GIS," In Geoinformatics, 2009 17th International Conference, IEEE, 2009, pp. 1-5.

[10] A. Pejic, S. Pletl, and B. Pejic, "An expert system for tourists using Google Maps API," In 2009 7th International Symposium on Intelligent Systems and Informatics. IEEE., pp. 317-322, 2009.

[11] M. Nakajima, "Path planning using indoor map data generated by the plan view of each floor," Pictogram, Vol. 50, pp. 50, 2011 
[12] H. Hwangbo, J. Kim Z. Lee, and S. Kim, "Store layout optimization using indoor positioning system," International Journal of Distributed Sensor Networks, Vol. 13 No. 2, pp. 1550147717692585, 2017.

[13] Ryder, K. J. "Designing and Publishing Indoor Maps for Patients and Visitors in an Academic Teaching Hospital," Masters dissertation. Dublin: Royal College of Surgeons in Ireland, 2015.

[14] H. Tang, T. Amuneke, J. Lantigua, H. Zou, W. Seiple and Z. Zhu, "Indoor Map Learning for the Visually Impaired," The journal on technology and persons with disabilities, pp. 192-207, 2017.

\section{BIOGRAPHIES OF AUTHORS}

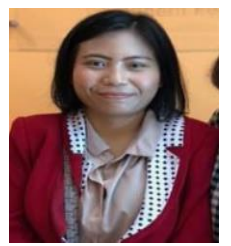

Supattra Puttinaovarat is a PhD lecturer at Faculty of Science and Industrial Technology, Prince of Songkla University, Surat Thani Campus. Her research interest includes Geographic Information System, Remote Sensing, Machine Learning and Information Technology.

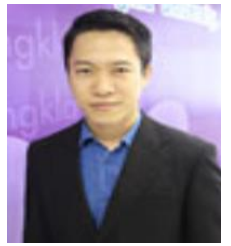

Suwat Jutapruet is a Phd lecturer at Faculty of Science and Industrial Technology, Prince of Songkla University, Surat Thani Campus. His research interest includes Marine Biodiversity, Marine Mammals, Dolphins and Information Technology.

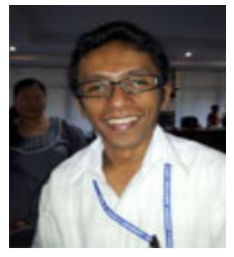

Aekarat Saeliw is a lecturer at Faculty of Science and Industrial Technology, Prince of Songkla University, Surat Thani Campus. His research interest includes Information Technology and Mobile Application.

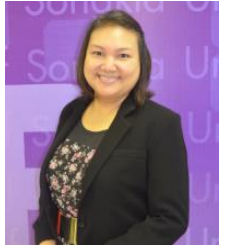

Siwipa Pruitikanee is a lecturer at Faculty of Science and Industrial Technology, Prince of Songkla University, Surat Thani Campus. Her research interest includes Information Technology and Mobile Application.

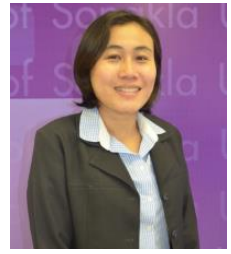

Jinda Kongcharoen is a PhD lecturer at Faculty of Science and Industrial Technology, Prince of Songkla University, Surat Thani Campus. Her research interest includes Statistics, Applied Statistics and Information Technology.

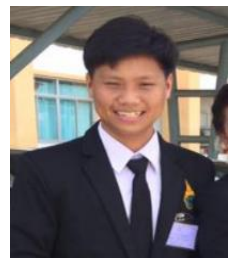

Watchara Jiamsawat received the Bachelor of Information Technology degree from Prince of Songkla University, Surat Thani Campus. His research interest includes Information Technology and Mobile Application.

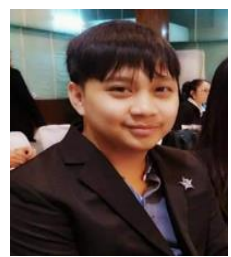

Suchakree Limpasamanon received the Bachelor of Information Technology degree from Prince of Songkla University, Surat Thani Campus. His research interest includes Information Technology and Mobile Application. 